\title{
Evaluating Silicone Rubber Materials and Fillers for Outdoor Insulator Housings and Sheds in Accelerating Aging of Environmental Stress
}

\author{
Member \\ X. Wang \\ (Akita University) \\ Student Member \\ S. Kumagai \\ (Akita University) \\ Member \\ N. Yoshimura \\ (Akita University)
}

\begin{abstract}
SUMMARY
The comparison tests between two types of silicone rubber (SR) materials such as a high temperature vulcanized silicone rubber (HTVSR) and a modified silicone rubber (MSR) by ethylene-vinyl-acetate (EVA), and two fillers such as alumina trihydrate (ATH) and magnesia hydrate (MH) are made in the accelerating aging of artificial environment stress, i.e. high temperature, ultraviolet (UV) ray exposure, corona, acid rain, and water-absorbing. The surface appearance, hydrophobicity, and tracking resistance of samples before and after aging are assessed. The degradation characteristics of base rubber materials and the effect of fillers are discussed furthermore. Research results show that in the designed environmental stress, HTVSR performs better than MSR, and that the sample with ATH filler performs better than that with MH filler. Acid rain and water-absorbing have little effect on the tracking resistance of SR. The degradation effect of UV-ray exposure is largest among the environmental stresses. The hydrophobicity and tracking resistance of HTVSR are not affected in thermal stress. The EVA composition in MSR makes it weaker to resist environmental stress. This research may provide a reference for the further modification of SR to meet the needs of application in more severe outdoor environment and contamination.
\end{abstract}

Keywords: silicone rubber, degradation, environmental stress, aging, tracking, hydrophobicity

\section{INTRODUCTION}

The polymer insulating materials for outdoor application are destined to suffer from environmental stress [1-3]. Owing to their superior contamination performance, better dielectric characteristics and light weightiness, the composite insulating materials have got a wide use in the application of outdoor $\mathrm{HV}$ insulator housings in replacement of porcelain or glass. However, environmental stress and contamination could exert a large degradation effect on the outdoor composite insulators so that the surface of insulator could degrade, hydrophobicity could decrease, the contaminant properties could be cut down, and tracking and discharge could occur to lead to failure, breakdown or flashover of insulation [1-2]. A lot of literature have reported the degradation of outdoor polymer insulating materials aged in artificial environmental stress and in field service [4-5].

The environmental stresses, i.e. ambient influences should cover not only weather factors but also the contaminants. Among them, those, which are important and influential in material degradation, include heat, sunlight, acid rain, ozone, water-immersing, and so on. It is known that high ambient temperature can cause thermal oxidation and thermal degradation of polymer material so that the lifetime of materials is shorten [3]. The main reason that sunlight exerts aging and degradation effect on organic materials is that sunlight can irradiate UV-ray, which could initiate the decomposition of polymeric molecule [6]. The acid anhydrite in acid rain can attack the weak bond of polymer and dissolve the inorganic filler [7-8]. Ozone from atmosphere and corona discharge can give rise to the degradation of material surface [9]. The outdoor insulating materials in service are subjected to numerous wet and dry circle. Water-absorbing of material can decrease the hydrophobicity of materials. Among the changes which the environmental stress makes in insulating materials, the decreasing hydrophobicity and tracking resistance are the useful indicator of the material 
degradation as a dielectric.

Silicone rubber materials are the widely-used composite materials in outdoor insulation for their superior contaminant performances over the other composite insulating materials. Their performances in the environmental stress are of great concerns [10-11]. Though a great number of papers have been published on this subject, it is still necessary to make further efforts in studying the influences of more severe environmental conditions and increasing contaminants on varied silicone rubber materials.

HTVSR is generally used as insulator housings or sheds in outdoor insulation for its better contaminant performance. But the high cost of HTVSR material imposes restrictions on its wide application. EVA is a polyolyfin material, of low-cost and better dielectric characteristic, and has a good elasticity and flexibility. But, the EVA material degraded easily in environmental stress [7]. It is suggested that the blending composite of HTVSR with EVA can make best use of the advantage and avoid the weak points of two materials, i.e. not only decrease the cost, but also acquire the desired performances to improve the cold-resistance of silicone rubber materials, and to increase the elasticity and flexibility But, the performances of the modified HTVSR by EVA, i.e. MSR, in environmental stress need to be testified.

ATH filler is always used to enhance the resistance of silicone rubber to damage from dry band arcing owing that not only ATH has the higher thermal conductivity than the base silicone rubber to absorb the heat from discharge, but also its decomposition in ignition will decrease the concentration of conductive carbon. MH almost has the same characteristics as ATH. ATH releases the crystal water, i.e. ATH thermally decomposes, at $250{ }^{\circ} \mathrm{C}$ and $500{ }^{\circ} \mathrm{C}$ twice, but $\mathrm{MH}$ releases the crystal water at about 340 ${ }^{\circ} \mathrm{C}$. The mixed filler of ATH and MH is expected to broaden the scope of releasing temperature of crystal water so as to enhance the resistance to ignition and flaming further.

In this paper, the samples, made of HTVSR and MSR materials and filled with $\mathrm{ATH}$ and $\mathrm{MH}$, are subjected to various environmental stresses and contaminants such as heat, UV-ray, corona, acid rain, and water-immersing. The surface appearance, hydrophobicity, and tracking resistance of silicone rubber materials before and after aging are investigated. The degradation characteristics of base rubber materials and the effect of fillers are discussed furthermore to make a comparison of them.

\section{EXPERIMENTS}

\subsection{Samples}

In this paper, three types of samples are used to compare with each other. The characteristics of sample materials are shown in Table 1. The filler of HTVSR and MSR-A is alumina trihydrate
(ATH). The base polymer material of MSR-B is the same as MSR-A, but its filler is composed of ATH and MH. The properties of ATH and MH fillers are shown in Table 2 [12]. To compare HTVSR with MSR-A can show the benefits of

Sample (composition wt ratio)

HTVSR

ATH (50)

MSR-A（EVA:HTVSR = 7:3）

ATH (50)

MSR-B (EVA:HTVSR $=7: 3$ )

ATH (30)\& MH (20)

Table 2 The properties of fillers in samples

\begin{tabular}{lcc}
\hline Properties & ATH & MH \\
\hline Molecular formula & $\mathrm{Al}_{2} \mathrm{O}_{3} \cdot 3 \mathrm{H}_{2} \mathrm{O}$ & $\mathrm{Mg}(\mathrm{OH})_{2}$ \\
particle form & plate & amorphous \\
particle size $(\mu \mathrm{m})$ & $0.2 \sim 5$ & $40 \sim 80$ \\
Specific gravity & 2.42 & 2.40 \\
Hardness & 3 & 3 \\
Specific heat $\left(\mathrm{cal} / \mathrm{g} \cdot{ }^{\circ} \mathrm{C}\right)$ & 0.28 & 0.28 \\
Heat conductivity $\left(\mathrm{W} / \mathrm{m} \cdot{ }^{\circ} \mathrm{C}\right)$ & 3 & - \\
Linear expansion $\left(10-5 /{ }^{\circ} \mathrm{C}\right)$ & 15 & - \\
Dissociation temperature $\left({ }^{\circ} \mathrm{C}\right)$ & $250 \& 500$ & 340 \\
\hline
\end{tabular}

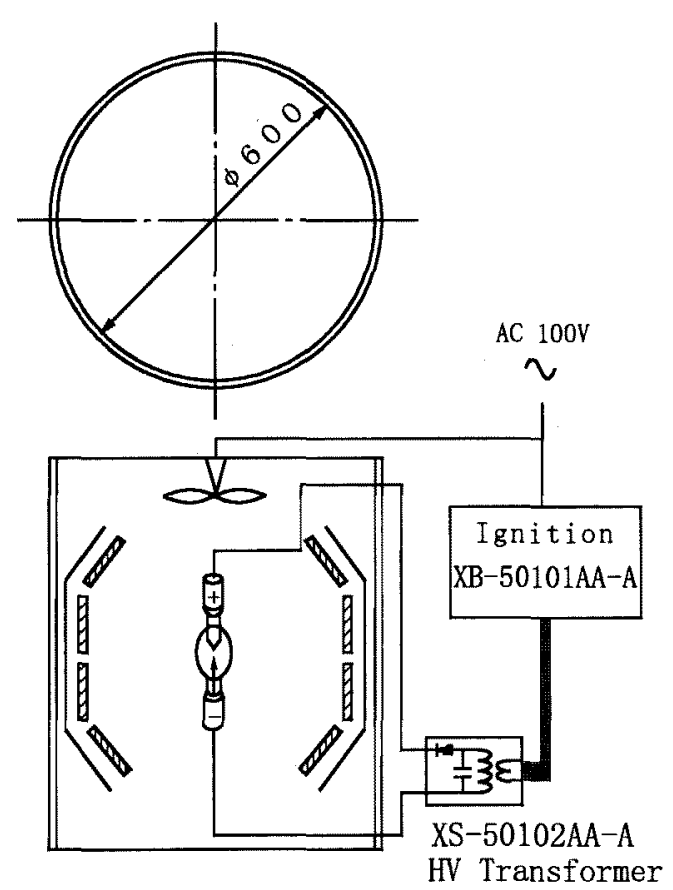

Fig. 1 Aging in UV-ray exposure house 
materials, and to compare MSR-A with MSR-B can show the effect of ATH and MH fillers. The size of sample refers to IEC Standards 587 , and is taken as $120 \times 50 \times 5 \mathrm{~mm}^{3}$ [13].

\subsection{Aging}

Thermal aging The thermal stress is applied to sample by two procedures. One is that the sample is subjected to thermal aging at $80{ }^{\circ} \mathrm{C}$ for 20 days, $200{ }^{\circ} \mathrm{C}$ and $300{ }^{\circ} \mathrm{C}$ for 100 hours in an oven before tracking test. The thermal aging at $80^{\circ} \mathrm{C}$ is designated to testify the long-time performance of sample materials under the worse circumstances, i.e. working at the higher temperature. The short-time thermal aging at $200{ }^{\circ} \mathrm{C}$ and $300{ }^{\circ} \mathrm{C}$ are used to analyze thermal stability of materials. Another is that the tracking test is applied to the sample in the 80 ${ }^{\circ} \mathrm{C}$ ambient condition in order to study the tracking characteristics at high temperature.

UV-ray exposure aging UV-ray exposure aging is applied to compare between the resistance of sample materials against weather degradation. It is already known that the spectrum of Xenon lamp approximates to the sunlight. Silicone rubber samples are exposed to UV-ray in a UV-ray exposure house, in which a Xenon lamp of UXL-500D type is installed. The cooling of sample is done by a fan as shown in Fig. 1. Assuming that the whole radiation energy which the Xenon lamp emitted is absorbed by the samples without any leakage, it is estimated that the accelerating rate of artificial UV exposure is about 117 [6]. But, this includes much safety factor, and neglects the effects of other factors. The radiation dosage which the samples absorbed in the actual test is much lower, the estimation seems to be of more allowance.

Acid rain aging The accelerating aging of artificial acid rain is applied based on the investigation of acid rain. The composition of artificial acid rain, as shown in Table 3, agrees with that of the actual acid rain [14]. The $\mathrm{pH}$ value of artificial acid rain is 2.1 and its conductivity is $7000 \mu \mathrm{S} / \mathrm{cm}$. The accelerating aging rate of ingredients of artificial acid rain is 500 times as great as the actual one. 30 days aging in artificial acid rain approximates to 40 years in field experience [7]

Corona exposure aging The erosion and degradation of insulating materials caused by ozone mainly come from corona discharge, and the ionization and activation of gas atom in atmosphere by UV-ray. In this research, corona discharge is applied to generate the ozone ambient as shown in Fig. 2. The corona equipment is confined in a box to keep the ozone concentration. The samples are aged by corona and ozone between the glass plates.

Water absorbing The sample is immersed in about $100{ }^{\circ} \mathrm{C}$ distilled water for some days to investigate water absorbance and its influence on hydrophobicity and tracking resistance.

\subsection{Degradation assessment}

The surface hydrophobicity of samples is evaluated by contact angle. The water absorbance in water-immersing, and the weight

Table 3 Ingredients of artificial acid rain Unit: gram/2 liter

\begin{tabular}{lc}
\hline Ingredients & Contents \\
\hline $\mathrm{NH} 4 \mathrm{Cl}$ & 1.00 \\
$\mathrm{NaCl}$ & 2.55 \\
$\mathrm{KCl}$ & 0.18 \\
$\mathrm{HNO}_{3}$ & 0.90 \\
$\mathrm{MgSO}_{4}$ & 1.05 \\
$\mathrm{CaSO}_{4} \cdot 2 \mathrm{H}_{2} \mathrm{O}$ & 0.90 \\
\hline
\end{tabular}
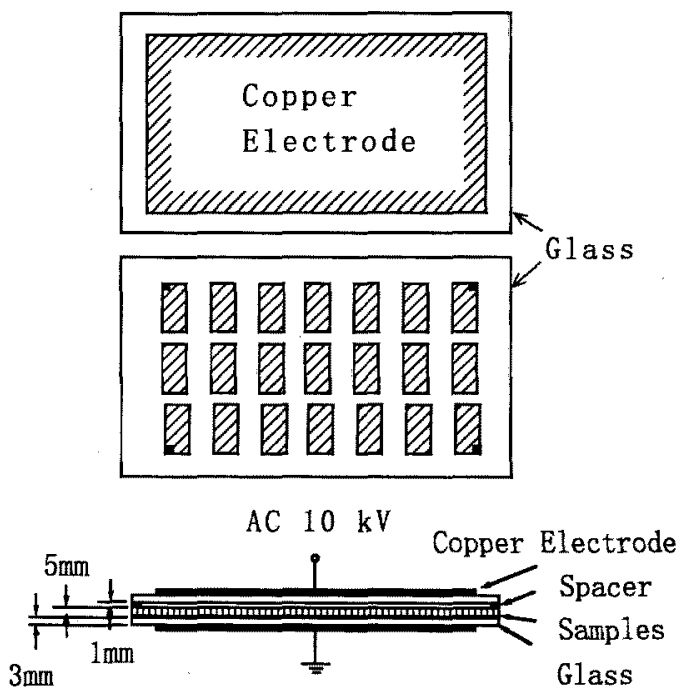

Fig. 2 Corona experimental diagram

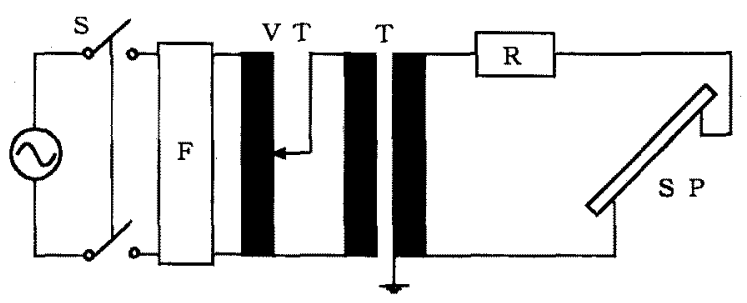

S--power supply switch VT--variable ratio transformer

$\mathrm{R}$--series resistor T----high voltage transformer

V--voltmeter SP--specimen

F--overcurrent relay

Fig. 3 Tracking experimental diagram of IEC 587 method 
loss in the aging of corona and acid rain are investigated.

Tracking resistance The Inclined Plane Method in IEC Standard 587 is applied to evaluate tracking resistance of sample as shown in Fig. 3. The preferred test voltage, AC $4.5 \mathrm{kV}$ is used as tracking voltage. The preferred criterion $\mathrm{A}$ (the end point is reached when the value of the current in the high voltage circuit through the specimen exceeds $60 \mathrm{~mA}$ ) is selected for determining the end point of the test. The contaminant consists of $0.1 \mathrm{NH}_{4} \mathrm{Cl}$ (ammonium chloride) and $0.02 \%$ iso-octylphenoxypolyethoxyethanol (a non-ionic wetting agent) in deionized water. Its conductivity is $2400 \mu \mathrm{S} / \mathrm{cm}$, and $\mathrm{pH}$ value is 5.85 [13].

\section{EXPERIMENTAL RESULTS}

\subsection{Degradation of materials structure}

Surface appearance has a close relation with the performance of hydrophobicity. The photograph pictures in Fig. 4 are the degraded surface of MSR-A samples aged in corona ambient and UV-ray, respectively. It is clear that the material surface suffers a large erosion and attack. The powdered surface of sample consists of filler resulting from UV exposure, what is called, "chalking." The white crystal on sample aged in ozone is nitrate and oxalate with crystal water, which is the characteristics of corona aging.

Figures 5-6 are the SEM results of aged samples, respectively. Due to the erosion and degradation effect of environmental stress, the material surface becomes chalking and rougher. By .comparison, we can see that under environmental stress, MSR-A and MSR-B degrade more easily than HTVSR. Figure 5 shows that even though MSR-B is composed of the same base polymer material as MSR-A, because the fillers in them are different, the surface degradation of the former is much larger than the latter.

Figure 7 shows the weight loss of samples in corona aging. The weight loss of samples increases with the aging time, and

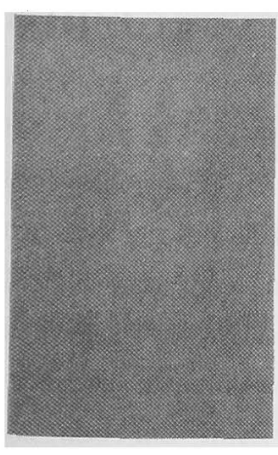

Virgin

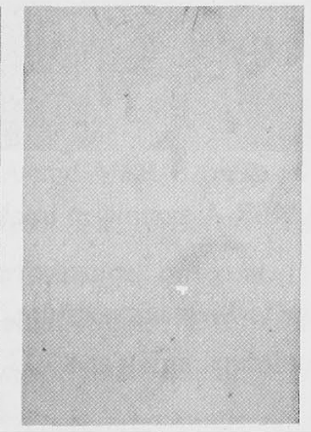

Aged in UV-ray

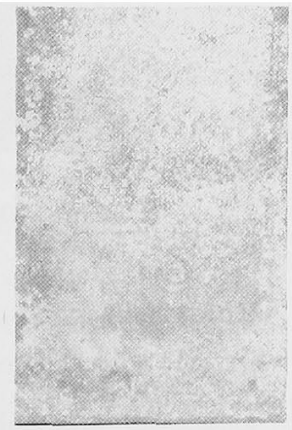

Aged in corona
Fig. 4 Photograph pictures of surface appearance of MSR-A sample. Sample size: length $\times$ width $=50 \times 35 \mathrm{~mm}$.

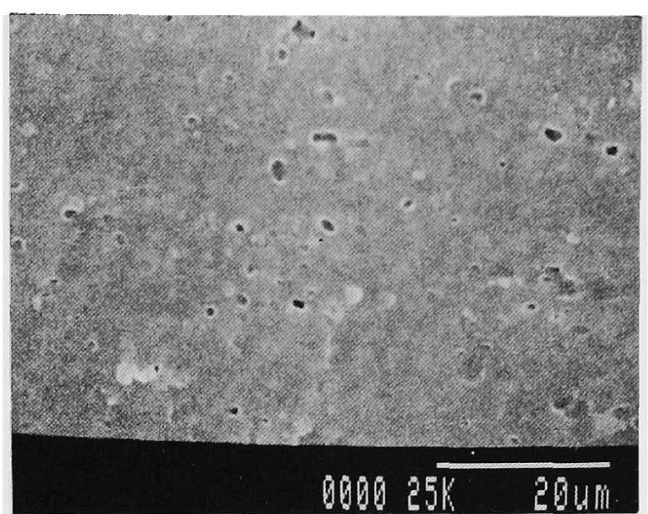

HTVSR

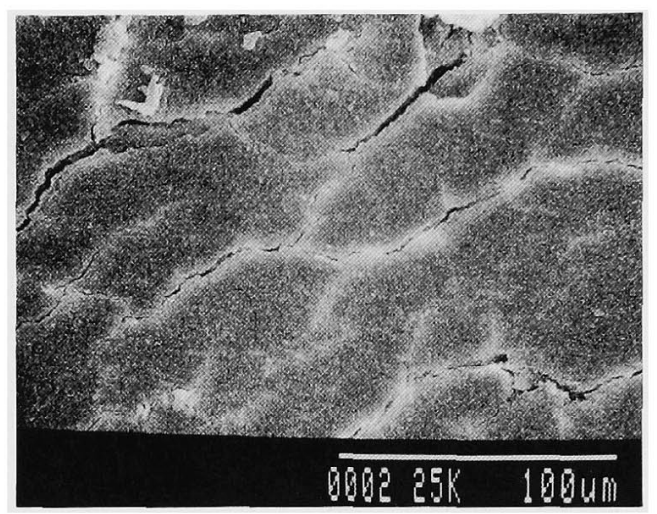

MSR-A

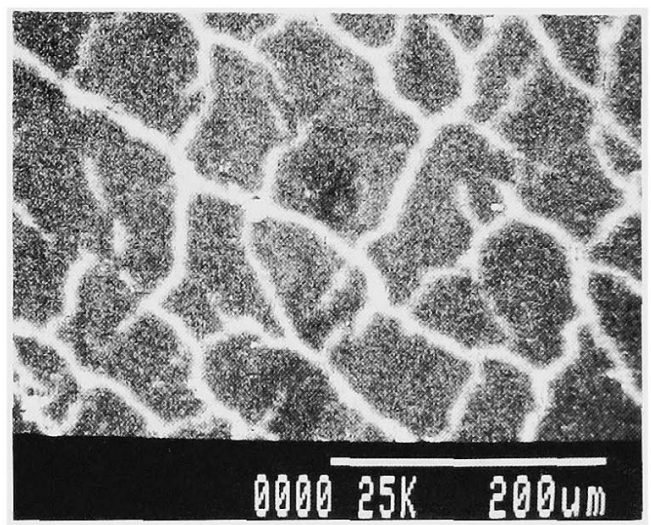

MSR-B

Fig. 5 SEM of samples aged in UV environment

that of HTVSR in corona aging is less than those of MSR-A and MSR-B. Figure 8 is the weight loss of samples aged in acid rain. It is obvious that the weightiness of SR decreases with the aging time. The weight loss of MSR-B is the least among three types of samples, and that of MSR-A is larger than that of HTVSR.

Figure 9 shows that the water absorbance of sample materials increases with the immersing time. The water absorbance of MSR-A is less than that of HTVSR, but that of MSR-B is the largest among those of three types of samples. 


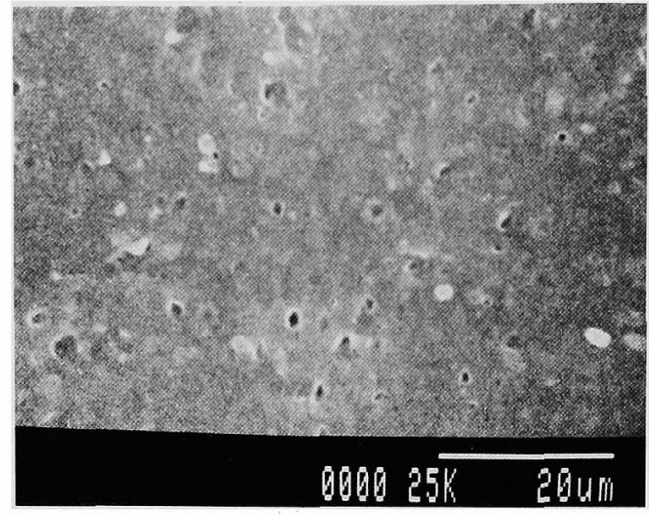

HTVSR

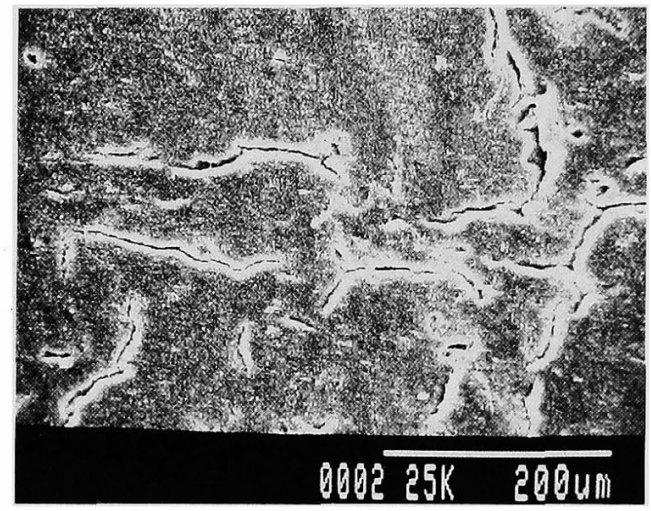

MSR-A

Fig. 6 SEM of samples aged in corona environment

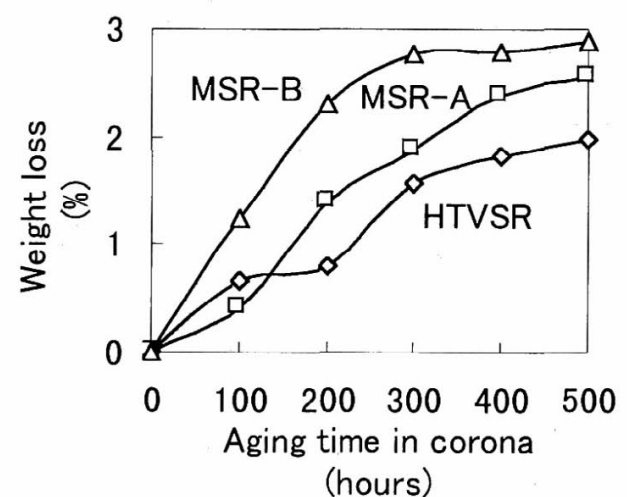

Fig. 7 Weight loss of samples in corona aging

\subsection{Contact angle}

The measured contact angles of samples before and after aging are shown in Table 4. The contact angle decreases in some extent with the aging time. And, the contact angles of MSR-A and MSR-B degrade more than that of HTVSR. The loss of Hydrophobicity is the common characteristic of sample aged in environmental stress except for thermal stress. It is interesting that the contact angle of HTVSR is not influenced by thermal aging, and increases a little. Because the EVA composition in

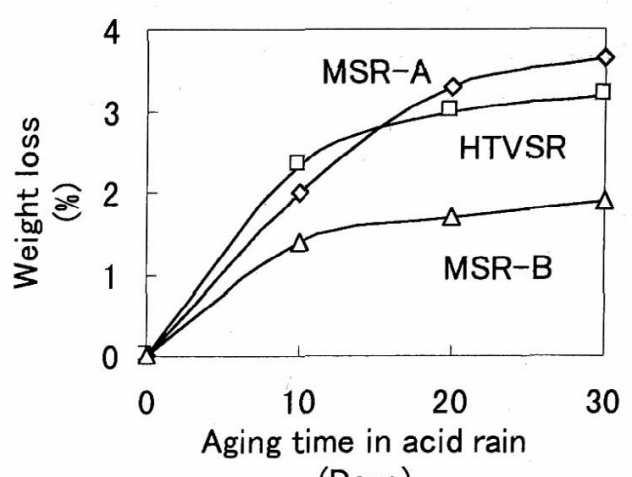

(Days)

Fig. 8 Weight loss of samples aged in acid rain

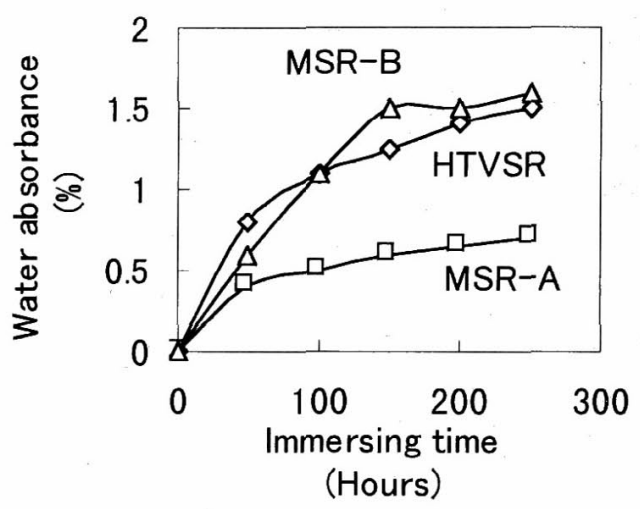

Fig. 9 Water absorbance of samples with the immersing time

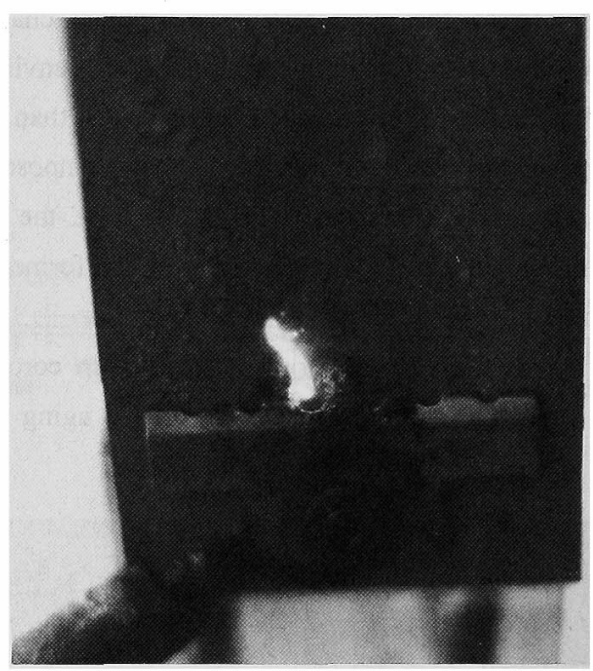

Fig. 10 MSR-A sample in tracking test

MSR cannot stand up to high temperature, MSR-A and MSR-B are only subjected to thermal aging at $80^{\circ} \mathrm{C}$.

\subsection{Tracking resistance}

Figure 10 is the MSR-A sample in tracking test. The test results of tracking resistance of virgin and the aged samples are 
Table 4 Contact angle

\begin{tabular}{|c|c|c|c|c|}
\hline Aging item $A$ & Aging conditions & HTVSR & MSR-A & MSR-B \\
\hline \multicolumn{2}{|l|}{ Virgin } & 113 & 94 & 112 \\
\hline & $80{ }^{\circ} \mathrm{C} 20$ days & 110 & 98 & 107 \\
\hline \multirow[t]{3}{*}{ Thermal Aging } & ng $200{ }^{\circ} \mathrm{C} 100$ hours & 123 & - & - \\
\hline & $300{ }^{\circ} \mathrm{C} 100$ hours & 125 & -- & - \\
\hline & 250 hours & 102 & 80 & 72 \\
\hline UV-ray & 500 hours & 97 & 65 & 61 \\
\hline \multirow[t]{2}{*}{ Exposure } & 1000 hours & 94 & 67 & 63 \\
\hline & 1500 hours & 94 & 64 & 45 \\
\hline \multirow[t]{2}{*}{ Corona } & 500 hours & 108 & 70 & 73 \\
\hline & 30 days & 108 & 91 & 93 \\
\hline \multirow[t]{3}{*}{ Acid rain } & 60 days & 110 & 89 & 91 \\
\hline & 90 days & 110 & 92 & 96 \\
\hline & 50 hours & 100 & 60 & 68 \\
\hline \multirow{3}{*}{$\begin{array}{l}\text { Water } \\
\text { absorbing }\end{array}$} & 100 hours & 98 & 58 & 66 \\
\hline & 150 hours & 96 & 60 & 68 \\
\hline & 200 hours & 95 & 64 & 65 \\
\hline
\end{tabular}

shown in Table 5. It is evident that environmental stress will affect the tracking resistance of SR materials. After samples are aged in environmental stresses except for thermal stress, the failure time of tracking decreases. The results shows that the thermal stress has no effect on the tracking resistance of HTVSR. All the samples can withstand the erosion of acid rain and immersing in water. The tracking resistance of HTVSR is little influenced by the environmental stress on the whole.

\section{DISCUSSION}

Experimental results reported here show that HTVSR performs better than MSR in the designed environmental stress. The EVA composition in MSR-A and MSR-B makes them weaker to resist the environmental stress. The different fillers in MSR-A and MSR-B make their performances different. It can be asserted that in the same environmental stress, the different degradation extent of sample materials is attributed not only to their base polymer but also the filler. Therefore, understanding of the aging processes of environmental stress affecting the sample materials is important to make comparison between them and to ensure their satisfactory performance in service.
Owing that the Si-O bond in silicone rubber has a high bond dissociation energy, the silicone rubber has a high heat resistance against tracking and discharge as well as degradation from environmental stress. Aging at $80{ }^{\circ} \mathrm{C}$ or much higher temperature has no effect on the contact angle and tracking resistance of HTVSR, and the result of tracking test at $80{ }^{\circ} \mathrm{C}$ ambient temperature remains the same as that at room temperature. That the contact angle of HTVSR increases after thermal aging at temperature higher than $80^{\circ} \mathrm{C}$, is mainly attributed to the diffusion of hydrophobic low-weight-molecular liquids from the bulk to surface. It is said that the thermal aging can activate the LWM polymer liquids in bulk and make them more mobile [5,

Table 5 Failure time of tracking test (Hour) *

Aging item Aging conditions HTVSR MSR-A MSR-B

\begin{tabular}{|c|c|c|c|c|}
\hline \multicolumn{2}{|l|}{ Virgin } & $>6$ & $>6$ & $>6$ \\
\hline & $80^{\circ} \mathrm{C}$ ambient** & $>6$ & $70 \mathrm{~min}$ & $55 \mathrm{~min}$ \\
\hline Thermal & $80{ }^{\circ} \mathrm{C} 20$ days ${ }^{* * * *}$ & $>6$ & $>6$ & $36 \mathrm{~min}$ \\
\hline \multirow[t]{2}{*}{ Aging } & $200^{\circ} \mathrm{C} 100$ hours $* * *$ & $>6$ & -- & -- \\
\hline & $300{ }^{\circ} \mathrm{C} 100$ hours $* * *$ & $>6$ & -- & -- \\
\hline \multirow{4}{*}{$\begin{array}{l}\text { UV-ray } \\
\text { Exposure }\end{array}$} & 250 hours & $31 \mathrm{~min}$ & $33 \mathrm{~min}$ & $22 \mathrm{~min}$ \\
\hline & 500 hours & $92 \mathrm{~min}$ & $52 \mathrm{~min}$ & $19 \mathrm{~min}$ \\
\hline & 1000 hours & $68 \mathrm{~min}$ & $41 \mathrm{~min}$ & $27 \mathrm{~min}$ \\
\hline & 1500 hours & $56 \mathrm{~min}$ & $49 \min$ & $24 \mathrm{~min}$ \\
\hline Corona & 500 hours & $141 \mathrm{~min}$ & $22 \min$ & $19 \mathrm{~min}$ \\
\hline \multirow{3}{*}{ Acid rain } & 30 days & $>6$ & $>6$ & $>$ \\
\hline & 60 days & $>6$ & $>6$ & 6 \\
\hline & 90 days & $>6$ & $>6$ & 6 \\
\hline \multirow{4}{*}{$\begin{array}{l}\text { Water } \\
\text { absorbing }\end{array}$} & 50 hours & $>6$ & $>6$ & $>6$ \\
\hline & 100 hours & $>6$ & $>6$ & 6 \\
\hline & 150 hours & $>6$ & $>6$ & $>6$ \\
\hline & 200 hours & $>6$ & $>6$ & $>6$ \\
\hline
\end{tabular}

Note:

* The preferred criterion A in IEC Standard 587 is selected for determining the end point of the test.

** Samples are subjected to tracking test at $80{ }^{\circ} \mathrm{C}$ ambient temperature.

*** Samples are subjected to thermal aging at $80{ }^{\circ} \mathrm{C}, 200{ }^{\circ} \mathrm{C}$ and $300{ }^{\circ} \mathrm{C}$ before tracking test. 
11]. The increasing hydrophobicity is available to improve resistance to tracking so that the tracking resistance of HTVSR does not decrease after thermal aging. The resistance to tracking of MSR-A or MSR-B decreases for the polyolyfin composition of EVA cannot withstand high temperature.

The experimental results show that the base polymer material degrades after UV-ray exposure. UV-ray is of large energy and can dissociate the weak bond of polymer molecular chains. The radical of broken bond will further initiate the chain dissociation reaction by the further action of UV-ray, and results in the low density area and micro defects forming on the surface so that surface appearance of material becomes worse, contact angle decreases, and the tracking resistance is cut down. Though the hydrocarbon bond of methyl in silicone rubber is weak, owing to the electronic shielding effect of Si-O bond, it obtains the additional potential energy from $\mathrm{Si}-\mathrm{O}$ bond so that it cannot be easily dissociated by UV-ray [15]. The hydrocarbon bond of methyl of EVA composition in MSR is weaker than that in silicone rubber, so that MSR degrades more easily than HTVSR.

Like the aging effect of UV-ray on polymer insulating materials, the corona can also break the weak bond of polymer molecular chains. The ozone from corona is active, and easily combines with the broken bond to initiate the chain dissociation reaction. Polymeric material degrades so large that the weightiness decreases after aging in corona. The resistance of MSR to corona and ozone is weaker than that of HTVSR for the EVA composition in them.

The most severe influence of acid rain on the materials is the erosion effect of severe acid of the low $\mathrm{pH}$. The inorganic filler which plays an role in improving tracking resistance and mechanical performance of the silicone rubber material is hydrophilic and easily dissolves into acid rain. The particle size of ATH filler is $0.2-5 \mu \mathrm{m}$ in general. The dissolution of filler will leave the same size defect in the surface layer [7]. The weight loss of MSR-B is less than that of MSR-A in Fig. 8, which indicates that the MH dissolves in acid rain not so easily as ATH does. The weak link bonds in silicone rubber molecular structure also suffer easily from acid rain. The EVA composition makes MSR easily affected by acid rain [7] so that MSR has the larger weight loss than HTVSR. Due to the erosion and degradation effect of acid rain, the insulator surface becomes rougher and the concentration of hydrophobic methyl groups decreases so that the hydrophobicity decreases in some extent. However, the experimental results show that artificial acid rain does not affect the tracking resistance of silicone rubber materials, which implies that silicone rubber materials can withstand the erosion of acid rain.

After water-absorbing, some amount of water has been absorbed in the shallow layer of material surface for the inorganic filler is hydrophilic and absorbs water, which will increase the surface energy of material and enhance the affinity of surface material for water, i.e. the hydrophilicity. In addition, the long-term water-absorbing will dissolve the low-weightmolecular polymeric material in surface layer to make the material surface lack of hydrophobic material. Although the hydrophobicity decreases after water-absorbing, the tracking resistance is not influenced, the reason being that the absorbed water will be released in the dry band arcing of tracking, acting as the crystal water in ATH or MH, to decrease the discharge heat and restrict the forming of conductive carbon. Owing that the polyolyfin materials such as EVA have less water absorbance than silicone rubber, the water absorbance of MSR is less than that of HTVSR. But, because that the larger particle size of $\mathrm{MH}$ in MSR-B makes the hydrophilic filler uneasily encapsulated in the hydrophobic polymer material so that MSR-B has the larger water absorbance than these of HTVSR and MSR-A as shown in Fig. 9.

After aging in environmental stress, the surface layer of SR materials degrades $[3,4]$. Consequently, the hydrophobicity decreases. The reduction of hydrophobicity and the degraded surface will further lead to the initiation of tracking phenomena. Therefore, the tracking resistance of material decreases. On the whole, HTVSR shows larger resistance to aging of environmental stress than MSR. Owing that the hydrocarbon bonds of polyolyfin in EVA are weaker to resist against the environmental stress, MSR degrades easily.

According to the theory of two phases blending of polymer or rubber with filler, if the particle size of the disperse phase (here the filler) is too large to well distribute in continuous phase (here the base rubber), the mechanical properties of material in environmental stress will be decreased, and the rubber material degrades easily, leading to fatigue failure, i.e. "cracking." Considering the data in Table 2, the particle size of MH is much larger than that of $\mathrm{ATH}$ so that it is not easy for $\mathrm{MH}$ to be evenly blended in silicone rubber materials. This is the reason why after UV-ray exposure, the MSR-B has more cracking on its surface than MSR-A in Fig. 5, and after corona aging, the weight loss of MSR-B is larger than that of MSR-A in Fig. 7.

\section{CONCLUSIONS}

The performances of silicone rubber materials HTVSR and MSR, and the effect of fillers of ATH and MH in thermal aging, UV-ray exposure, corona, acid rain, and water-absorbing are investigated. Experimental results show that HTVSR performs better than MSR in the designed environmental stress. Acid rain and water-absorbing have little effect on the tracking resistance 
of SR. The degradation effect of UV exposure is largest among the environmental stresses. The hydrophobicity and tracking resistance of HTVSR are not affected in thermal stress. The EVA composition in MSR makes it weaker to resist the environmental stress. The sample filled with ATH shows better performances than that filled with $\mathrm{MH}$.

\section{FURTHER WORK}

It is known that the deterioration of outdoor insulation in field is related to the composite of environmental stresses, i.e. their overlapping effect, which is severer than that each of them takes effect alone. We shall report our further research work which lays an emphasis on the multiple-stress aging.

\section{REFERENCES}

[1] S. Ezure, Y. Imai, K. Kadotani, M. Mase, T. Nishino, Y. Kamiya, and K. Idokawa, "Weather Resistance of Polymeric Materials for Outdoor High Voltage Use," Plenary Session of Power Energy Division of IEEJ, pp. 394-395, 1994.

[2] N. E. Frost, G. Xu, and P. B. McGrath, "An Examination of the Environments for Aging of Polymer," Annual Report CEIDP, pp. 354-357, 1997.

[3] W. T. Starr, "Polymer Outdoor Insulation," IEEE Trans. Electr. Insul., Vol. 25, pp. 125-136, 1990.

[4] T. Sorqvist and A. E. Vlastos, "Performances and Aging of Polymeric Insulators," IEEE Trans. PD, Vol. 12 No. 4, pp. 1657-1665, 1997.

[5] R. S. Gorur and T. Orbeck, "Surface Dielectric Behavior of Polymeric Insulation under HV Outdoor Conditions," IEEE Trans. Electr. Insul. Vol. 26, pp. 1064-1072, 1991.

[6] S. Kumagai, X. Wang, and N. Yoshimura, "Effect of UV-ray on Tracking Resistance of Outdoor Polymer Insulating materials," IEEJ Trans., Vol. 117-A, No. 3, pp. 289-298, 1997.

[7] X. Wang, S. Kumagai, K. Kobayashi, and N. Yoshimura, "Degradation of Surface Contamination Performances of Outdoor Polymer Insulator Owing to Acid Rain," IEEJ Trans., Vol. 118-A, pp. 502-508, 1998.

[8] D. Y. Li, S. Hwangbo, D. H. Park, K. S. Suh, and M. K. Han, "The Tracking Phenomena and Chemical Degradation of Elastomer Aged by the Acid Rain," Proc. 25th Symp. Electr. Insul. Mat., Nagoya, Japan, Sept., 1993, pp. 95-100.

[9] Y. Koshino, I. Umeda, and M. Ishiwari, "Deterioration of Silicone Rubber for Polymer Insulators by Corona discharge and Effects of Fillers," IEEJ Trans., Vol. 118-A, No. 6, pp. 683-688, 1998.

[10] S. M. Gubanski, "Properties of Silicone Rubber Housing and Coatings," IEEE Trans. Electr. Insul. Vol. 27 No. 2, pp. 374-381,
1992.

[11] R. S. Gorur, G. G. Karady, A. Jagota, M. Shah, and A. M. Yates, "Aging in Silicone Rubber used for Outdoor Insulation," IEEE Trans. Power Delivery, Vol. 7 No. 2, pp. 525-533, 1992.

[12] IEEJ Technical Report, "Effect of Additives and Fillers in Solid Insulating Materials," Vol. II , No. 342, July, 1990.

[13] IEC Standard Publication 587, "Test Methods for Evaluating Resistance to Tracking and Erosion of Electrical Insulating Materials used under Severe Ambient Condition," 1984.

[14] The Meteorology Bureau of Japan, "Report of Second Investigation of Acid Rain," Acid Rain Seminar, July, 1994.

[15] W. Noll, "Chemistry and Technology of Silicones," Academic Press, New York, 1968.

(Received 22 June 1998, accepted for publication 20 Nov. 1998)

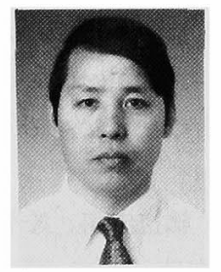

X. Wang (member) He was born in Oct., 1957. He received his B. E. in Electrical Insulation from Xi'an Jiaotong University in 1981; M. E. in High Voltage Engineering from Wuhan Hydraulic \& Electrical Engineering University in 1986; PhD. from Xi'an Jiaotong University in 1992. Now he works in Akita University. His interests include electrical insulation in high voltage engineering, and insulating materials.

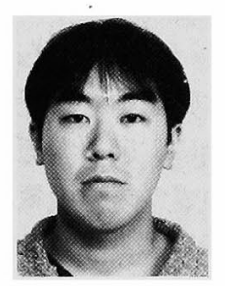

S. Kumagai (student member) $\mathrm{He}$ was born in July, 1972. He received his B. E. and M. E. in Electrical and Electronic Engineering from Akita University in 1995 and 1997, respectively. He currently studies on outdoor polymer insulating materials in Akita University as a doctoral course student.

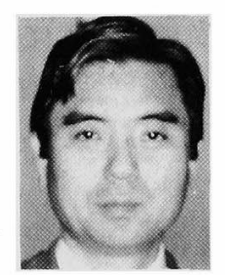

N. Yoshimura (member) $\mathrm{He}$ was born in Nov., 1943. He received his B. E. and M. E. in Electrical and Electronic Engineering from Akita University in 1967 and 1969 respectively; PhD from Nagoya University in 1975. He joined Akita University in 1969, became professor in 1983, and has been the Dean of Mining College of Akita University since 1995. From Jan., 1978 to Sept., 1979, he worked in Clarkson University of USA as visiting scholar. His research interests include dielectric materials of polymer, ceramics, and semiconductive ceramics. 